\title{
FUNDAMENTALISMO RELIGIOSO VERSUS RACIONALISMO Y MODERNIDAD
}

\author{
RELIGIOUS FUNDAMENTALISM VERSUS RATIONALISM AND \\ MODERNITY \\ (D) Manuel Paz y Miño ${ }^{*}$ \\ mpaz@ulima.edu.pe \\ ${ }^{1}$ Universidad de Lima, Lima, Perú
}

*Correspondencia: Manuel Paz y Miño. Email: mpaz@ulima.edu.pe

Recibido: 20.02.2020 | Aprobado: 12.03.2020

\section{RESUMEN}

El fundamentalismo concebido como la expresión fanática y extrema de una ideología religiosa (y/o política) que se considera a sí misma como poseedora de una verdad inequívoca, pues se la cree proveniente de lo Alto, no es un fenómeno nuevo, está latente en cualquier religión. Surge como una reacción, que incluso puede ser violenta, al cambio de mentalidad y costumbres producido por personas a las que se considera pecadoras, malvadas, engañadas o endemoniadas. En circunstancias de gran ignorancia y necesidad material los fundamentalistas crecerán en número, pero eso no impide que puedan surgir en cualquier clase social o época. Solo una temprana educación humanista y científica podrá prever la aparición de grupos fundamentalistas en el seno de una sociedad, o al menos que lo hagan en gran número.

Palabras clave: fundamentalismo, fanatismo, discriminación, intolerancia.

\begin{abstract}
Fundamentalism conceived as the fanatic and extreme expression of a religious (and/or political) ideology that considers itself as having an unequivocal truth, because it is believed to come from above, is not a new phenomenon, it is latent in any religion. Fundamentalism arises as a reaction, which can even be violent, to the change of mentality and customs produced by people who are considered sinners, evil, deceived or demonized. In circumstances of great ignorance and material need fundamentalists will grow in number, but that does not prevent them from arising in any social class or time. Only an early humanist and scientific education can foresee the emergence of fundamentalist groups within a society, or at least do so in a large number of them.
\end{abstract}

Keywords: fundamentalism, fanaticism, discrimination, intolerance. 


\section{LOS CREYENTES PROMEDIO}

Todo creyente promedio en cualquier parte del mundo cree en alguna divinidad y en algún tipo de conciencia después de la muerte, y que sus creencias son ciertas, pero no hará proselitismo, discutirá, perseguirá o matará a otros que tengan otras, distintas a las suyas. Como cualquier persona con creencias religiosas, las usará como un soporte y una esperanza ante las necesidades, avatares y tragedias que se le pueden presentar en su vida. Es decir, la religión no es solo creer en el más allá sino también creer que la divinidad afecta el más acá o que lo que hacemos repercutirá en la otra vida. La mayoría de fieles es fideísta, esto es, creen y punto, no necesitan estudiar su fe ni mucho menos la cuestionan, la han aprendido desde muy niños de sus padres y estos a su vez de los suyos hasta remontarnos a la época en que se impuso su religión, muchas veces por medio de la conquista política más que por la conversión y el convencimiento personales. De ahí que el Estado y la religión siempre se han apoyado mutuamente.

\section{RELIGIONES Y MODERNIDAD SECULAR}

En Occidente, debido a la aparición del racionalismo moderno y corrientes filosóficas contemporáneas, como el positivismo, el marxismo, el neo positivismo, el existencialismo ateo, etc., los descubrimientos científicos aportados por Kepler, Galileo y Newton, el libro Sobre el origen de las especies (1859) de Darwin, y avances sociales y políticos como la democracia y el secularismo, distintas facciones del cristianismo imperante reaccionaron. Así, por ejemplo, se desencadenó un conflicto violento entre teólogos y científicos sobre la teoría de la evolución y la interpretación bíblica en Europa y los EE.UU. (Sánchez 1998: 14)

Con el paso del tiempo, las iglesias, tanto la católica como las evangélicas, se han tenido que adaptar a los cambios y nuevas ideas que se han dado con el paso del tiempo. De ese modo, diversas denominaciones protestantes de tinte modernista han aceptado que sus ministros puedan casarse, la equidad de género y, por eso mismo, que las mujeres formen parte del clero, el derecho de los homosexuales a casarse e incluso algunas y la Iglesia católica la teoría de la evolución de las especies. Con todo, el proyecto moderno, con la ciencia y las ideologías seculares a la cabeza, pretendieron enterrar a Dios, reemplazar las religiones y sus absolutos sin éxito hasta el presente.

Como reacción a eso, los creyentes extremos respondieron reafirmando su fe: no solo creyendo que sus creencias son ciertas, sino que son absolutamente verdaderas ya que provienen de lo Alto y que, por ende, las de los demás, que son diferentes a las suyas, son erradas, falsas, malvadas o incluso producto del demonio, según su lógica basada en la supuesta revelación escrita de Dios a los hombres. Por otro lado, cuando las tradiciones, incluyendo la religión, son consideradas como ya no más necesarias, aparece el fundamentalismo, justamente cuando la sociedad se atomiza, se fragmenta, haciendo dificultoso a sus miembros identificarse con ella (Sánchez 1998: 315-316) pues lo que antes se consideraba verdadero y sagrado ya no lo, es más.

$\mathrm{Y}$ así esos creyentes extremos pueden pensar que donde imperan los niveles de corrupción, delincuencia, decadencia y maldad se debe a que muchas religiones han perdido fieles y protagonismo social y político precisamente por ceder ante el modernismo secular sin Dios. Y justamente por eso aparece el fundamentalismo religioso como una 
respuesta a un mundo donde ya no hay más una identidad propia, certezas ni refugio para los que creen que Dios sigue vivo que y la religión provee el camino a una vida mejor, más segura y feliz.

\section{FUNDAMENTALISMO RELIGIOSO}

Como ya es sabido, históricamente se considera que el fundamentalismo religioso se originó como un movimiento dentro de los grupos evangélicos en los EE.UU. a principios del siglo pasado, y que propugnó el regreso a los fundamentos bíblicos del cristianismo, tanto en las doctrinas como en las prácticas, ya que para ellos la Biblia es la Palabra de Dios y, por ende, es absolutamente verdadera, perfecta y sin errores, debiendo, en ese sentido, ser interpretada literalmente en lo fundamental: que el dios judeo-cristiano creó al mundo en siete días y descansó en el séptimo o sábado, que hubo un diluvio universal, que al ser "detenido el sol” la luz del día duró más de las habituales doce horas, que algunos profetas y Jesús mismo hicieron milagros, o que éste nació de una virgen, murió, resucitó y hasta a la diestra de Dios, su padre, que los pecadores, incluidos los homosexuales, "practicantes de perversión" y los incrédulos (agnósticos, ateos y humanistas seculares), considerados "necios", irán al infierno, que la mujer deberá estar sujeta a su marido, así como el esclavo a su amo, que el sexo es algo vergonzoso, la masturbación abominación, y que no se debe tener coito antes del matrimonio o, peor aún, el sexo sólo es para procrear.

Si bien los creyentes tenían problemas, en el siglo xix, con la evolución darwiniana, a fines de ese siglo los tuvieron más aún con la alta crítica de la Biblia que planteaba que el Pentateuco no fue escrito por Moisés, ni los Salmos por David, que la concepción virginal de Jesús era una alegoría y que las diez plagas de Egipto fueron desastres naturales (Armstrong 2004: 192-194).

Ciertamente en las otras vertientes del cristianismo, católicas o no, puede verse también el fenómeno fundamentalista o extremista. Por ejemplo, para las más de 120 iglesias "manipuladoras de serpientes (venenosas)" en sus servicios religiosos, Jesús prometió que ellas no dañarían a sus seguidores, pero a pesar de que ya murieron varios fieles y pastores por mordeduras mortales, los miembros de tales congregaciones siguen fieles a la promesa; algunos cristianos extremistas han bombardeado clínicas y asesinado médicos y enfermeras abortistas, o a fieles del Islam en sus propias mezquitas.

Para los testigos (cristianos) de Jehová es pecado mortal recibir trasfusiones de sangre, incluso para salvar las vidas de sus hijos, pues la Biblia prohíbe comerla lo que para ellos incluiría ingresarla al cuerpo, para los adventistas del séptimo día es pecado trabajar el día sábado (idea proveniente del Génesis judío). Y en otras religiones puede aparecer el mismo fenómeno fundamentalista con grupos extremistas o integristas dentro del judaísmo, el islamismo, el hinduismo, el budismo, etc. Siendo la distinción más importante entre los religiosos fundamentalistas y los religiosos conservadores su anti modernismo militante (Hood et al., 2005: 1-2).

Para el movimiento laico sionista, la fundación del Estado de Israel en 1945 simplemente es el resultado de la búsqueda de una tierra donde los judíos puedan vivir en paz luego del holocausto sufrido a manos de los nazis sin que eso signifique que sea un 
Estado teocrático contrario a otras religiones como querían los fundamentalistas que incluso asesinaron a musulmanes y planeaban destruir mezquitas en 1984 (Sánchez 1998: $242-243 ; 247-248)$.

Pero la visión secularizada del Estado de Israel provoca una respuesta fundamentalista, especialmente por parte de grupo de intelectuales que habían sido no creyentes pero que volvieron a su fe primigenia: para ellos la fundación de Israel ocupando tierras palestinas cumple una promesa de Dios. Para los fundamentalistas o integristas islámicos, o islamistas (Escribano, 2001. 16-17) cualquier creyente no puede interpretar el Corán por sí solo, necesita de un experto que lo guíe y le dé la interpretación correcta. Los antecedentes de su aparición se deben al conflicto de siglos con Occidente, a los movimientos independentistas que llevó a los nuevos estados laicos a imitar a los occidentales, la fundación del Estado de Israel y las consecuentes guerras que ocasionaron pérdida de territorios árabes, el boom del petróleo de la década de 1970, etc. (Escribano, 2001: 14-16).

Los fundamentalistas islámicos, no sólo se basan en su interpretación del Corán, sino en las tradiciones de Mahoma y las enseñanzas teológicas y legales, quieren imponer la ley islámica o sharia (Escribano, 2001: 17) y para promover y luchar por la defensa de sus creencias y valores usan incluso el terror. Es así que llevaron y llevan a cabo la guerra santa contra los infieles occidentales a través de atentados con bombas contra embajadas, aviones o edificios (Escribano, 2001: 84-85). Algunos acentúan que el islamismo no sólo sería un fundamentalismo que quiere la vuelta al Corán y al Profeta, sino que además plantea "un proyecto político que no necesariamente ha de ser incompatible con Occidente y la modernidad", como si sucede con los otros fundamentalismos (Escribano, 2001: 17-18).

Los islamistas o integristas musulmanes se basan en las doctrinas puritanas del wahabismo, salafismo, y mahdismo, aparecidas en los siglos xviii y xix, y en las organizaciones políticas de la Hermandad Musulmana y la Comunidad Islámica, del siglo $\mathrm{xx}$, cuyo accionar se basaba en cinco lemas que influenciaron en los islamistas posteriores: Alá es nuestra meta, el profeta Mahoma es nuestro ejemplo, el Corán es nuestra ley, la yihad es nuestro camino, y morir en nombre de Alá es lo que queremos (Escribano, 2001: 20-22). Para los islamistas, ningún gobernante de los actuales Estados musulmanes es un musulmán "verdadero" (Ali, 2002: 337).

Los fundamentalistas hindúes promueven una interpretación literal védica que restaure el sistema de castas haciendo a las castas inferiores esclavas, subyugando absolutamente a la mujer y la prohibición de las otras religiones y de los símbolos occidentales. En general, al ser una expresión autoritaria de las religiones, el fundamentalismo puede provocar reacciones violentas, y puede expresarse en dos campos: el doctrinal e intelectual, esto es, el religioso y el político. Y así hay, entonces, más de un fundamentalismo, algunos que no les interesa lo político, y otros que van tras el poder usando lo religioso (Sánchez 1998: 88-89). 


\section{CONSECUENCIAS DEL FUNDAMENTALISMO}

Entre las consecuencias del fundamentalismo tenemos a los prejuicios, la discriminación, la intolerancia, el fanatismo, la persecución, la explotación física y el abuso psicológico dentro de determinada religión. El fundamentalista ante los que piensan diferente tendrá prejuicios, adelantará juicios de valor con respectos a ellos no por su carácter o acciones sino por sus ideas distintas descalificando a sus propugnadores. Tiene juicios de valor elaborados de antemano sobre el mundo y las demás personas que piensan diferente que él lo que le lleva a discriminarlas y no tolerarlas. Así, tendrá prejuicios contra ellas y las pondrá a todas en un mismo saco: el de los impíos o perversos. Eso puede traer como consecuencia que el fundamentalista se convierta en un fanático, un apasionado de sus creencias que trate a los que no piensan como él de modo violento verbal y físicamente, de ese modo estaría infringiendo la ley civil pero no, según su visión, la de Dios.

Empero cuando los fundamentalistas fanáticos están respaldados por el poder del Estado o lo manejan ellos mismos, la cuestión empeora: empiezan a perseguir, a ir tras sus opositores ideológicos, o si no los hacen arrestar, torturar, aprisionar, condenar y hasta ejecutar a los que creen y piensan de modo distinto a ellos, si no se retractan y cambian de ideas, si no se arrepienten de su modo perverso y sin dios de pensar y actuar. Hay casos célebres de esto último dentro del cristianismo católico (Bruno, Galileo) y muchos más no tan conocidos por la Inquisición en Europa y América, o por el evangélico (Servet, las brujas de Salem). Por lo tanto, los fundamentalistas religiosos necesitan del poder secular para reafirmar y defender sus creencias, las que consideran divinamente ciertas. Pero también hay fundamentalismos políticos en el sentido de que los seguidores de determinada ideología del poder crean que la suya es la más perfecta y acabada y, de ese modo, es incuestionable: comunista o neoliberal.

Tanto los fundamentalistas religiosos como los políticos pueden verse a sí mismos como los poseedores de una verdad infalible y los que creen en cosas distintas a ellos están equivocados, engañados o, peor, son engendros del mal y, por lo tanto, dañinos. Los miembros de ambos tipos de fundamentalistas refuerzan psicológica y sociológicamente sus creencias al estar en contacto con otros correligionarios. El fundamentalismo está contra el bien común pues busca homogenizar la sociedad en un único sentido: el que cree verdadero (Sánchez 1998: 257, es mítico (ib., 273) lo que choca con la realidad variada y múltiple. Pero también el fundamentalismo, sobre todo musulmán, ha ocasionado miedo e inseguridad en Occidente provocando nuevas intolerancias religiosas: prohibición del uso público de la burca y nicab musulmanes, prendas de vestir que cubre el cuerpo y la cara, o solo la cabeza y la cara menos los ojos respectivamente, en países específicos como Francia, Bélgica, Austria y Dinamarca, o la prohibición solamente para las trabajadoras del Estado que tienen relación con el público en Alemania, o en todas las oficinas estatales de Holanda (Rodríguez Martínez et al.).

\section{CAUSAS DEL FUNDAMENTALISMO}

Entre las causas del fundamentalismo están: el inculcamiento o lavado cerebral desde la más tierna infancia, la enseñanza de una sola religión en las escuelas públicas o privadas, la mucha ignorancia, la falta de pensamiento crítico, las carencias materiales (la 
pobreza) y culturales, así como la necesidad de identificarse con un grupo. Aunado al rechazo de la modernidad con su relativización de los valores incluyendo lo bueno y verdadero, y su ausencia de seguridades y absolutos como dios mismo. Los padres pueden sembrar y perpetuar el fundamentalismo religioso en sus hijos al no hablarles o exponerles a otros puntos de vista y otras religiones. La escuela también puede hacer lo suyo al enseñar a los alumnos una sola visión del mundo, una única religión.

Muchas veces las personas de mente estrecha, iletradas o de escasa educación, de baja condición socioeconómica y simplistas pueden ser víctimas fáciles de fundamentalistas fanáticos que no necesariamente serán de su mismo status. Hay quienes carecen de los medios y las capacidades intelectuales para discernir y distinguir las ideas oscurantistas de las ilustradas. Es peor si el sistema educativo del país no enseña a los niños y jóvenes a pensar críticamente. En busca de gente que les pueda ayudar en sus necesidades materiales o para no sentirse marginados y rezagados las personas, por lo general, muchos buscan integrarse e identificarse con un grupo, y muchas veces lo encuentran en uno de tipo fundamentalista De ese modo las creencias fundamentalistas les dan a sus seguidores un marco de orientación y devoción a sus seguidores (Fromm, 1970: 69), una filosofía unificadora de la vida, un sentido de coherencia y un significado (propósito, valores, eficacia y autoestima), a sus vidas (Hood et al., 2005: 30-46) así como trascendencia en alguna forma de vida eterna (ib.: 208), a diferencia de un ateísmo vulgar, nihilista y simplón que no se apoye en la filosofía y valores humanistas o el conocimiento científico.

Por lo general, no abundan los fundamentalistas religiosos donde hay una educación científica y una sociedad de bienestar. Pero una excepción notoria son los EE.UU. donde existen muchos grupos evangélicos fundamentalistas incluyendo doctores en alguna ciencia. Además, también diversos casos de masacres han sido perpetrados por supremacistas blancos ahí mismo, en sociedades de bienestar como Noruega y Nueva Zelanda, en nombre de la civilización occidental y cristiana. Lo que demuestra que ninguna sociedad --atrasada o adelantada—puede evitar desarrollar sus propios dementes y criminales.

\section{¿Cómo prevenir el fundamentalismo religioso?}

Básicamente con la existencia de un Estado laico que no favorezca a ninguna religión o punto de vista no creyente, pero sí el conocimiento de las humanidades (incluyendo el estudio de las religiones y las visiones seculares) y las ciencias. De ese modo, en las escuelas públicas no se lavará el cerebro de los niños y adolescentes ni se les inculcará un solo punto de vista limitado del mundo (Paz y Miño 2004). Una buena política educativa centrada en valores como la equidad, la justicia y la libertad, así como en las humanidades y las ciencias fomentará visiones del mundo realistas y democráticas donde se acepte y comprenda al que piensa y luce diferente. Y, por supuesto, los gobiernos que fomenten esto también deben actuar de ese modo.

Ahora bien, en los países donde el Estado laico moderno aún es un proyecto político, pues las religiones intervienen en sus políticas públicas, los librepensadores organizados deben promover, en la sociedad de la que forman parte, el pensamiento crítico a través de diversas actividades culturales y educativas (como video-foros, debates, 
seminarios, talleres, etc.) o por internet especialmente orientadas al público infantil y juvenil, cuyos miembros serán los ciudadanos del mañana. O en todo caso a través de engorrosas, lentas demandas legales y judiciales, y no siempre exitosas, para esos librepensadores organizados dependiendo del Estado de derecho de cada país, pues en unos hay más libertad u opresión que en otros para la libertad de pensamiento.

\section{CONCLUSIONES}

\section{E1 fundamentalismo:}

- $\quad$ no es un fenómeno exclusivo de nuestro tiempo ni de una cultura o clase social en particular, pero crece mucho más en seguidores mientras más iletrados y pobres sean.

- $\quad$ está latente en cualquier religión o ideología política.

- promueve formas conservadoras o arcaicas de pensar y actuar.

- $\quad$ cree en una única verdad: la suya propia.

- $\quad$ es intolerante con formas liberales o modernistas de pensar y actuar.

- $\quad$ necesita del poder político para defenderse de sus supuestos archi enemigos y así declararlos fuera de la ley, perseguirlos, aprisionarlos o ejecutarlos.

- $\quad$ tiende a expresarse de forma violenta tanto psicológica como físicamente.

- $\quad$ es una traba para el avance del conocimiento científico y el cambio social.

- $\quad$ no crece fácilmente donde hay avance científico y bienestar social.

- en definitiva, el fundamentalismo es literalista, autoritario, discriminatorio, intolerante y fanático (Paz y Miño 2004²).

\section{REFERENCIAS BIBLIOGRÁFICAS}

Ali, Tariq. 2002. El choque de los fundamentalismos: cruzadas, yihads y modernidad. Madrid: Alianza.

Armstrong, Karen. 2004. Los origenes del fundamentalismo en el judaísmo, el cristianismo y el islam. Barcelona: Tusquets.

Escribano, Lydia. 2001. El fundamentalismo islámico. Madrid: Acento.

Fromm, Erich. 1970. La revolución de la esperanza. Hacia una tecnología bumanizada. México: Fondo de Cultura Económica.

Hood, Ralph W; Hill, Peter C; Williamson, W. Paul. 2005. The psychology of religious fundamentalism. NY \& London: Guilford Press, 1st ed.

Nussbaum, Martha C. 2013. La nueva intolerancia religiosa: cómo superar la politica del miedo en una época de inseguridad. Barcelona: Paidós, 1a ed.

Paz y Miño, Manuel. "Discriminación religiosa en las escuelas públicas peruanas» en Eupraxofía Nro. 4, Lima: AERPFA, mayo 2004, pp. 110-2.

Paz y Miño, Manuel. "Sobre la discriminación, el fanatismo, los prejuicios y la intolerancia" en $\mathrm{CD}$ del XV Congreso Interamericano y II Congreso 
Iberoamericano de Filosofía: Tolerancia, Lima: Pontificia Universidad Católica del Perú, 12 al 16 de enero de $2004^{2}$.

Rodríguez Martínez, Marta \& Eloisa Covelli con EFE. 27 de febrero de 2019. “¿Qué países europeos prohíben el burka?” en: https://es.euronews.com/2018/08/08/que-paises-europeos-prohiben-el-burka-

Rodríguez Zahar. El fundamentalismo religioso y el Estado en el siglo xx. Revista Mexicana de Política Exterior, n. 49, 1996, pp. 244-56.

Sánchez Parodi, Horacio M. 1998. El fundamentalismo en la política. Buenos Aires: Depalma.

\section{CITAR COMO:}

Paz y Miño Conde, M. (2020). Fundamentalismo religioso versus racionalismo y modernidad. Puriq, 2(1), 28-35. https://doi.org/10.37073/puriq.2.1.67 